\title{
Fixed point for fuzzy mappings in different generalized types of metric spaces
}

\author{
A. Kamala,b,*, Asmaa M. Abd-Elal ${ }^{b}$ \\ ${ }^{a}$ Department of Mathematics, College of Science and Arts, AlMithnab, Qassim University, Buridah51931, Saudi Arabia. \\ ${ }^{b}$ Department of Mathematics and Computer Science, Faculty of Science, Port Said University, Port Said 42521, Egypt.
}

\begin{abstract}
The aim of the paper is to establish some fixed point theorems for fuzzy mappings satisfying an implicit relation in left and right quasi-metric spaces. These theorems generalize the corresponding results in [S. Heilpern, J. Math. Anal. Appl., 83 (1981), 566-569], [V. Popa, Stud. Cercet. Ştiinţ. Ser. Mat. Univ. Bacău, 7 (1997), 127-133].
\end{abstract}

Keywords: Fixed point, fuzzy mapping, lq-metric space, rq-metric space.

2020 MSC: 46E15, 47B33, 47B38, 54C35.

(C)2022 All rights reserved.

\section{Preliminaries}

In this section, we mention some concepts and results for fuzzy mappings in metric spaces.

In [8], an element in any fuzzy set has a degree of belonging, a membership function may be used in order to introduce the value of degree of belonging for any element to a set, the value of degree of belonging takes real values on the whole closed interval $[0,1]$. The membership function is

$$
\mu_{\mathrm{A}}: \mathrm{X} \longrightarrow[0,1]
$$

Let $(X, d)$ be a metric linear space. A fuzzy set in $X$ is a function $A: X \longrightarrow[0,1]$, i.e., it is an element of $\mathrm{I}^{\mathrm{X}}$ where $\mathrm{I}=[0,1]$. If $\mathrm{A}$ is a fuzzy set and $x \in X$, then the function value $A(x)$ is called the grade of membership of $x \in A$. The collection of all fuzzy sets in $X$ is denoted by $\mathfrak{F}(X)$. Let $A \in \mathfrak{F}(X)$ and $\alpha$-level set of $A$, defined by

$$
A_{\alpha}=\{x: A(x) \geqslant \alpha\} \text { if } \alpha \in(0,1]
$$

and

$$
A_{0}=\overline{\{x: A(x)>0\}},
$$

whenever $\overline{\{\}}$ is the closure of set (non fuzzy) \{\} .

\footnotetext{
*Corresponding author

Email addresses: ak.ahmed@qu.edu.sa, alaa_kamal@sci.psu.edu.eg (A. Kamal), asmaamoh1221@yahoo.com (Asmaa M. Abd-Elal)
}

doi: $10.22436 /$ jmcs.025.01.07

Received: 2020-12-25 Revised: 2021-04-02 Accepted: 2021-04-08 
Definition 1.1 ([5]). A fuzzy set $A$ in $X$ is an approximate quantity if its $\alpha$-level set is a nonempty compact subset(non fuzzy) of $X$ for each $\alpha \in[0,1]$. The set of all an approximate quantities denoted by $W^{*}(X)$, is a sub collection of $\mathfrak{F}(X)$.

Definition 1.2 ([5]). Let $X$ be an arbitrary set and $Y$ be a metric space. A mapping $F$ is said to be a fuzzy mapping if $F$ is a mapping from the set $X$ into $W^{*}(Y)$, i.e., $F(x) \in W^{*}(Y)$ for each $x \in X$.

Definition $1.3([5])$. Let $(X, d)$ be a metric space and let $A, B \in W^{*}(X), \alpha \in[0,1]$ and $C P(X)$ be a set of all nonempty compact subsets of $X$. Then it is defined the following

$$
\begin{array}{ll}
p_{\alpha}(A, B)=\inf \left\{d(x, y): x \in A_{\alpha}, y \in B_{\alpha}\right\}, & p(A, B)=\sup _{\alpha} p_{\alpha}(A, B), \\
D_{\alpha}(A, B)=H\left(A_{\alpha}, B_{\alpha}\right), & D(A, B)=\sup _{\alpha}\left\{D_{\alpha}(A, B): \alpha \in[0,1]\right\},
\end{array}
$$

where $D_{\alpha}$ is a $\alpha$-distance, $D$ is a distance between $A$ and $B$ and the Hausdorff distance $H$ is defined on subsets $A$ and $B$ in the collection $C P(X)$ such that

$$
H(A, B)=\max \left\{\sup _{a \in A} d(a, B), \sup _{b \in B} d(b, A)\right\} .
$$

Proposition 1.4 ([12]). If $\mathrm{A}, \mathrm{B} \in \mathrm{CP}(\mathrm{X})$ and $\mathrm{a} \in \mathrm{A}$, then there exists $\mathrm{b} \in \mathrm{B}$ such that

$$
d(a, b) \leqslant H(A, B) .
$$

Lemma 1.5 ([5]). Let $(X, d)$ be a metric space and let $x \in X, A \in W^{*}(X)$. Then $x \in A_{\alpha}$ or $\{x\} \subseteq A$ if and only if

$$
p_{\alpha}(x, A)=0 .
$$

Lemma $1.6([5])$. Let $(X, d)$ be a metric space and let $A \in W^{*}(X)$. Then

$$
p_{\alpha}(x, A) \leqslant d(x, y)+p_{\alpha}(y, A),
$$

for all $x, y \in X$ and $\alpha \in[0,1]$.

Lemma 1.7 ([5]). Let $(X, d)$ be a metric space and let $\left\{x_{0}\right\} \subseteq A$. Then

$$
p_{\alpha}\left(x_{0}, B\right) \leqslant D_{\alpha}(A, B),
$$

for each $\mathrm{A}, \mathrm{B} \in \mathrm{W}^{*}(\mathrm{X})$ and $\alpha \in[0,1]$.

Lemma 1.8 ([5]). Let $(X, d)$ be a metric space, $\mathrm{T}: \mathrm{X} \longrightarrow \mathrm{W}^{*}(\mathrm{X})$ be fuzzy mapping and $\mathrm{x}_{0} \in \mathrm{X}$. Then there exists $\mathrm{x}_{1} \in \mathrm{X}$ such that $\left\{\mathrm{x}_{1}\right\} \subset \mathrm{T}\left(\mathrm{x}_{0}\right)$.

Following Popa [13], let $G$ be the family of all continuous mappings $g:[0, \infty)^{6} \longrightarrow[0, \infty)$ satisfying the following properties:

$\left(\mathrm{g}_{1}\right) \mathrm{g}$ is non-decreasing in the $1^{\text {st }}$ coordinate and $\mathrm{g}$ is non-increasing in $3^{\text {rd }}, 4^{\text {th }}, 5^{\text {th }}$, and $6^{\text {th }}$ coordinate variables;

$\left(g_{1}\right)$ there exists $k \in(0,1)$ such that for every $u, v \in[0, \infty), g(u, v, u, v, u+v, 0) \leqslant 0$ implies $u \leqslant k v$;

$\left(g_{1}\right)$ if $u \in[0, \infty)$ such that $g(u, 0,0, u, 0, u) \leqslant 0$, then $u=0$.

\section{Fixed point theorems for fuzzy mappings in left quasi-metric spaces}

First, we give the concept of left quasi-metric spaces (abbrev., lq-metric spaces) as follows.

Definition 2.1. Let $X$ be a nonempty set. A map $d: X \times X \longrightarrow[0, \infty)$ is called a distance on $X$. A pair $(X, d)$ is said to be a distance space. Now, we list some conditions as follows:

(i) $d(x, y)=0$ or $d(y, x)=0$ if and only if $x=y$; 
(ii) $d(x, y) \leqslant d(z, x)+d(z, y)$,

for every $x, y, z \in X$. If $d$ satisfies the conditions (i) and (ii), then $(X, d)$ is called an lq-metric space.

Remark 2.2. Clearly, the concept of lq-metric spaces is a generalization of the concept of metric spaces.

Definition 2.3. Let $(X, d)$ be an lq-metric space. We say that $\left\{x_{n}\right\}$ lq-converges to $x$ if and only if $\lim _{n \rightarrow \infty} d\left(x_{n}, x\right)$ $=0$. In this case, $x$ is called lq-limit of $x_{n}$.

Definition 2.4. Let $(X, d)$ be an lq-metric space. We say that $\left\{x_{n}\right\}$ is Cauchy if and only if for every $\epsilon>0$ there exists a positive integer $N=N(\epsilon)$ such that $d\left(x_{n}, x_{m}\right)<\epsilon$ for all $n \geqslant m>N$.

Definition 2.5. An lq-metric space $(X, d)$ is complete if every Cauchy sequence in $X$ is lq-convergent.

Now, we state the following lemmae without proof.

Lemma 2.6. Let $(X, d)$ be an lq-metric space and let $x \in X, A \in W^{*}(X)$. Then $x \in A_{\alpha}$ (i.e., $\left.\{x\} \subseteq A\right)$ if and only if

$$
p_{\alpha}(x, A)=0 .
$$

Lemma 2.7. Let $(X, d)$ be an lq-metric space and let $\left\{x_{0}\right\} \subseteq A$. Then

$$
p_{\alpha}\left(x_{0}, B\right) \leqslant D_{\alpha}(A, B)
$$

for each $\mathrm{A}, \mathrm{B} \in \mathrm{W}^{*}(\mathrm{X})$ and $\alpha \in[0,1]$.

Lemma 2.8. Let $(X, \mathrm{~d})$ be an lq-metric space, $\mathrm{T}: \mathrm{X} \longrightarrow \mathrm{W}^{*}(\mathrm{X})$ be a fuzzy mapping and $\mathrm{x}_{0} \in \mathrm{X}$. Then there exists $\mathrm{x}_{1} \in \mathrm{X}$ such that $\left\{\mathrm{x}_{1}\right\} \subset \mathrm{T}\left(\mathrm{x}_{0}\right)$.

Lemma 2.9. Let $(\mathrm{X}, \mathrm{d})$ be an lq-metric space. Then any subsequence of lq-convergent sequence in $\mathrm{X}$ is lqconvergent.

Also, we state and prove the following lemma.

Lemma 2.10. Let $(X, d)$ be an lq-metric space and let $A \in W^{*}(X)$ and $A$. Then

$$
p_{\alpha}(x, A) \leqslant d(y, x)+p_{\alpha}(y, A),
$$

for each $\mathrm{A}, \mathrm{B} \in \mathrm{W}^{*}(\mathrm{X})$ and $\alpha \in[0,1]$.

Proof. We fined that

$$
p_{\alpha}(x, A)=\inf _{z \in A_{\alpha}} d(x, z) \leqslant \inf _{z \in A_{\alpha}}(d(y, x)+d(y, z))=d(y, x)+\inf _{z \in A_{\alpha}} d(y, z)=d(y, x)+p_{\alpha}(y, A) .
$$

Now, we are ready to state and prove our main theorem in the following way.

Theorem 2.11. Let $(X, d)$ be complete lq-metric space, $x_{0} \in X$, and $\mathrm{T}: \mathrm{X} \longrightarrow \mathrm{W}^{*}(\mathrm{X})$ be a fuzzy mapping. If there is a $\mathrm{g} \in \mathrm{G}$ such that, $\forall \mathrm{x}, \mathrm{y} \in \mathrm{X}$

$$
g(D(T x, T y), d(x, y), p(T x, x), p(T y, y), p(y, T x), p(x, T y)) \leqslant 0,
$$

then $\mathrm{T}$ has a fixed point. 
Proof. Let $x_{0}$ be an arbitrary point in $X$, then by Lemma 2.8, then there exists $x_{1} \in X$ such that $\left\{x_{1}\right\} \subset T x_{0}$. Also, for $x_{1} \in X$, there exists $x_{2} \in X$ such that $\left\{x_{2}\right\} \subset T x_{1}$. $\left(T x_{0}\right)_{1},\left(T x_{1}\right)_{1} \in C P(X)$, from Proposition 1.4, then $d\left(x_{2}, x_{1}\right) \leqslant D_{1}\left(T x_{1}, T x_{0}\right)$,

$$
\begin{aligned}
g & \left(d\left(x_{2}, x_{1}\right), d\left(x_{1}, x_{0}\right), d\left(x_{2}, x_{1}\right), d\left(x_{1}, x_{0}\right), d\left(x_{1}, x_{0}\right)+d\left(x_{2}, x_{1}\right), 0\right) \\
& =g\left(d\left(x_{2}, x_{1}\right), d\left(x_{1}, x_{0}\right), d\left(x_{2}, x_{1}\right), d\left(x_{1}, x_{0}\right), d\left(x_{1}, x_{0}\right)+d\left(x_{2}, x_{1}\right)+d\left(x_{2}, x_{2}\right), 0\right) \\
& \leqslant g\left(d\left(x_{2}, x_{1}\right), d\left(x_{1}, x_{0}\right), d\left(x_{2}, x_{1}\right), d\left(x_{1}, x_{0}\right), d\left(x_{1}, x_{0}\right)+d\left(x_{1}, x_{2}\right), 0\right) \\
& \leqslant g\left(d\left(x_{2}, x_{1}\right), d\left(x_{1}, x_{0}\right), d\left(x_{2}, x_{1}\right), d\left(x_{1}, x_{0}\right), d\left(x_{0}, x_{2}\right), 0\right) \\
& \leqslant g\left(D_{1}\left(T x_{1}, T x_{0}\right), d\left(x_{1}, x_{0}\right), p\left(T x_{1}, x_{1}\right), p\left(T x_{0}, x_{0}\right), p\left(x_{0}, T x_{1}\right), p\left(x_{1}, T x_{0}\right)\right) \\
& \leqslant g\left(D\left(T x_{1}, T x_{0}\right), d\left(x_{1}, x_{0}\right), p\left(T x_{1}, x_{1}\right), p\left(T x_{0}, x_{0}\right), p\left(x_{0}, T x_{1}\right), p\left(x_{1}, T x_{0}\right)\right) \leqslant 0 .
\end{aligned}
$$

From $\left(g_{2}\right)$, there exists $k \in(0,1)$ such that $d\left(x_{2}, x_{1}\right) \leqslant k d\left(x_{1}, x_{0}\right)$. Continuing in this way we produce a sequence $\left\{x_{n}\right\}$ in $X$ such that $x_{n} \subset T\left(x_{n-1}\right)$ and

$$
d\left(x_{n}, x_{n-1}\right) \leqslant k^{n-1} d\left(x_{1}, x_{0}\right) .
$$

It follows by induction that $d\left(x_{n}, x_{n-1}\right) \leqslant k^{n-1} d\left(x_{1}, x_{0}\right)$ for each $n \in \mathbb{N}$. Since

$$
\begin{aligned}
d\left(x_{n}, x_{m}\right) & \leqslant d\left(x_{n-1}, x_{n}\right)+d\left(x_{n-1}, x_{m}\right) \\
& \leqslant d\left(x_{n}, x_{n-1}\right)+d\left(x_{n}, x_{n}\right)+d\left(x_{n-2}, x_{n-1}\right)+d\left(x_{n-2}, x_{m}\right) \\
& \leqslant d\left(x_{n}, x_{n-1}\right)+d\left(x_{n-1}, x_{n-2}\right)+d\left(x_{n-1}, x_{n-1}\right)+\cdots+d\left(x_{m+1}, x_{m}\right) \\
& \leqslant\left[k^{n-1}+k^{n-2}+\cdots+k^{m}\right] d\left(x_{1}, x_{0}\right) \\
& \leqslant\left[k^{n-1}+k^{n-2}+\cdots\right] d\left(x_{1}, x_{0}\right) .
\end{aligned}
$$

Furthermore, for $n \geqslant m$ we have

$$
d\left(x_{n}, x_{m}\right) \leqslant \sum_{i=0}^{n-m-1} d\left(x_{n-i}, x_{n-i-1}\right) \leqslant \sum_{i=m}^{n-1} k^{i} d\left(x_{1}, x_{0}\right) \leqslant \frac{k^{m}}{(1-k)} d\left(x_{1}, x_{0}\right) .
$$

Then the sequence $\left\{x_{n}\right\}$ is Cauchy. Since $(X, d)$ is complete, then there exists $x^{*} \in X$ such that $\lim _{n \rightarrow \infty} x_{n}=x^{*}$. By Lemma 2.9, we obtain the $\lim _{n \rightarrow \infty} x_{n+1}=x^{*}$. By Lemma 2.7 and Lemma 2.10, we get

$$
p_{\alpha}\left(x^{*}, T x^{*}\right) \leqslant d\left(x_{n+1}, x^{*}\right)+p_{\alpha}\left(x_{n+1}, T x^{*}\right) \leqslant d\left(x_{n+1}, x^{*}\right)+D_{\alpha}\left(T x_{n}, T x^{*}\right)=d\left(x_{n+1}, x^{*}\right)+D_{\alpha}\left(x_{n+1}, T x^{*}\right),
$$

for each $\alpha \in[0,1]$. Taking supremum on $\alpha$ in the last inequality, we obtain from the property $\left(g_{1}\right)$ of $G$ that

$$
\begin{aligned}
& g\left(p\left(x_{n+1}, T x^{*}\right), d\left(x_{n}, x^{*}\right), d\left(x_{n+1}, x_{n}\right), p\left(x^{*}, T x^{*}\right)+d\left(x^{*}, x^{*}\right), d\left(x_{n+1}, x^{*}\right)+d\left(x_{n+1}, x_{n+1}\right), p\left(x_{n}, T x^{*}\right)\right) \\
& \quad \leqslant g\left(p\left(x_{n+1}, T x^{*}\right), d\left(x_{n}, x^{*}\right), d\left(x_{n+1}, x_{n}\right), p\left(T x^{*}, x^{*}\right), d\left(x^{*}, x_{n+1}\right), p\left(x_{n}, T x^{*}\right)\right) \\
& \quad \leqslant g\left(D_{1}\left(T x_{n}, T x^{*}\right), d\left(x_{n}, x^{*}\right), p\left(T x_{n}, x_{n}\right), p\left(T x^{*}, x^{*}\right), p\left(x^{*}, T x_{n}\right), p\left(x_{n}, T x^{*}\right)\right) \\
& \quad \leqslant g\left(D\left(T x_{n}, T x^{*}\right), d\left(x_{n}, x^{*}\right), p\left(T x_{n}, x_{n}\right), p\left(T x^{*}, x^{*}\right), p\left(x^{*}, T x_{n}\right), p\left(x_{n}, T x^{*}\right)\right) \leqslant 0 .
\end{aligned}
$$

As $n \rightarrow \infty$, we have that

$$
g\left(p\left(x^{*}, T x^{*}\right), 0,0, p\left(x^{*}, T x^{*}\right), 0, p\left(x^{*}, T x^{*}\right)\right) \leqslant 0 .
$$

By the condition $\left(g_{3}\right)$ of $G$, we have that $p\left(x^{*}, T x^{*}\right)=0$. So by Lemma 2.6 we conclude that $T$ has a fixed point.

Remark 2.12. Theorem 2.11 generalizes and improves Theorem 3.1 in [8], where $\mathrm{X}$ is complete lq-metric space instead of $X$ is complete metric linear space. 
Corollary 2.13. Let $(\mathrm{X}, \mathrm{d})$ be complete lq-metric space, $\mathrm{x}_{0} \in \mathrm{X}$, and $\mathrm{T}: \mathrm{X} \longrightarrow \mathrm{W}^{*}(\mathrm{X})$ be a fuzzy mapping. If there exists $k \in(0,1)$ such that

$$
\mathrm{D}(\mathrm{T} x, \mathrm{Ty}) \leqslant \mathrm{kd}(x, y) \text { for each } x, y \in X,
$$

then $\mathrm{T}$ has a fixed point.

Proof. We consider the function $\mathrm{g}:[0, \infty)^{6} \longrightarrow[0, \infty)$ defined by

$$
g\left(x_{1}, x_{2}, x_{3}, x_{4}, x_{5}, x_{6}\right)=x_{1}-k x_{2} .
$$

Since $\mathrm{g} \in \mathrm{G}$ we can apply Theorem 2.11 and obtain Corollary 2.13.

\section{Fixed point theorems for fuzzy mappings in right quasi-metric spaces}

Now, we introduce the concept of right quasi-metric spaces (abbrev., rq-metric spaces) as follows.

Definition 3.1. Let $X$ be a nonempty set. A map $d: X \times X \longrightarrow[0, \infty)$ is called a distance on $X$. A pair $(X, d)$ is said to be a distance space. Now, we list some conditions as follows:

(i) $d(x, y)=0$ or $d(y, x)=0$ if and only if $x=y$;

(ii) $d(x, y) \leqslant d(x, z)+d(y, z)$,

for every $x, y, z \in X$. If $d$ satisfies the conditions (i) and (ii), then $(X, d)$ is called an rq-metric space.

Remark 3.2. Clearly, the concept of rq-metric spaces is different generalization of the concept of metric spaces.

Definition 3.3. Let $(X, d)$ be an rq-metric space. We say that $\left\{x_{n}\right\}$ rq-converges to $x$ if and only if $\lim _{n \rightarrow \infty} d\left(x, x_{n}\right)$ $=0$. In this case, $x$ is called rq-limit of $x_{n}$.

Definition 3.4. Let $(X, d)$ be an rq-metric space. We say that $\left\{x_{n}\right\}$ is Cauchy if and only if for every $\epsilon>0$ there exists a positive integer $N=N(\epsilon)$ such that $d\left(x_{n}, x_{m}\right)<\epsilon$ for all $m \geqslant n>N$.

Definition 3.5. An rq-metric space $(X, d)$ is complete if every Cauchy sequence in $X$ is rq-convergent.

Now, we state the following lemmae without proof.

Lemma 3.6. Let $(X, d)$ be an rq-metric space and let $x \in X, A \in W^{*}(X)$. Then $x \in A_{\alpha}$ (i.e., $\left.\{x\} \subseteq A\right)$ if and only if

$$
p_{\alpha}(A, x)=0 .
$$

Lemma 3.7. Let $(X, d)$ be an rq-metric space and let $\left\{x_{0}\right\} \subseteq A$. Then

$$
p_{\alpha}\left(B, x_{0}\right) \leqslant D_{\alpha}(B, A),
$$

for each $\mathrm{A}, \mathrm{B} \in \mathrm{W}^{*}(\mathrm{X})$ and $\alpha \in[0,1]$.

Lemma 3.8. Let $(X, d)$ be an rq-metric space, $T: X \longrightarrow W^{*}(X)$ be a fuzzy mapping and $x_{0} \in X$. Then there exists $\mathrm{x}_{1} \in \mathrm{X}$ such that $\left\{\mathrm{x}_{1}\right\} \subset \mathrm{T}\left(\mathrm{x}_{0}\right)$.

Lemma 3.9. Let $(\mathrm{X}, \mathrm{d})$ be an rq-metric space. Then any subsequence of $\mathrm{rq}$-convergent sequence in $\mathrm{X}$ is $\mathrm{rq}-$ convergent.

Also, we state and prove the following lemma.

Lemma 3.10. Let $(X, d)$ be rq-metric space and let $A \in W^{*}(X)$. Then

$$
p_{\alpha}(A, x) \leqslant p_{\alpha}(A, y)+d(x, y),
$$

for each $\mathrm{A}, \mathrm{B} \in \mathrm{W}^{*}(\mathrm{X})$ and $\alpha \in[0,1]$. 
Proof. We fined that

$$
p_{\alpha}(A, x)=\inf _{z \in A_{\alpha}} d(z, x) \leqslant \inf _{z \in A_{\alpha}}(d(z, y)+d(x, y))=\inf _{z \in A_{\alpha}} d(z, y)+d(x, y)=p_{\alpha}(A, y)+d(x, y) .
$$

Now, we are ready to state and prove our main theorem in the following way.

Theorem 3.11. Let $(X, \mathrm{~d})$ be complete rq-metric space, $\mathrm{x}_{0} \in \mathrm{X}$, and $\mathrm{T}: \mathrm{X} \longrightarrow \mathrm{W}^{*}(\mathrm{X})$ be a fuzzy mapping. If there is a $\mathrm{g} \in \mathrm{G}$ such that, $\forall x, \mathrm{y} \in \mathrm{X}$,

$$
g(D(T x, T y), d(x, y), p(x, T x), p(y, T y), p(y, T x), p(T y, x)) \leqslant 0,
$$

then Thas a fixed point.

Proof. Let $x_{0}$ be an arbitrary point in $X$, then by Lemma 3.8, then there exists $x_{1} \in X$ such that $\left\{x_{1}\right\} \subset T x_{0}$. Also, for $x_{1} \in X$, there exists $x_{2} \in X$ such that $\left\{x_{2}\right\} \subset T x_{1} .\left(T x_{0}\right)_{1},\left(T x_{1}\right)_{1} \in C P(X)$, from Proposition 1.4, then $d\left(x_{1}, x_{2}\right) \leqslant D_{1}\left(T x_{0}, T x_{1}\right)$.

$$
\begin{aligned}
g & \left(d\left(x_{1}, x_{2}\right), d\left(x_{0}, x_{1}\right), d\left(x_{1}, x_{2}\right), d\left(x_{0}, x_{1}\right), d\left(x_{0}, x_{1}\right)+d\left(x_{1}, x_{2}\right), 0\right) \\
& =g\left(d\left(x_{1}, x_{2}\right), d\left(x_{0}, x_{1}\right), d\left(x_{1}, x_{2}\right), d\left(x_{0}, x_{1}\right), d\left(x_{0}, x_{1}\right)+d\left(x_{2}, x_{2}\right)+d\left(x_{1}, x_{2}\right), 0\right) \\
& \leqslant g\left(d\left(x_{1}, x_{2}\right), d\left(x_{0}, x_{1}\right), d\left(x_{1}, x_{2}\right), d\left(x_{0}, x_{1}\right), d\left(x_{0}, x_{1}\right)+d\left(x_{2}, x_{1}\right), 0\right) \\
& \leqslant g\left(d\left(x_{1}, x_{2}\right), d\left(x_{0}, x_{1}\right), d\left(x_{1}, x_{2}\right), d\left(x_{0}, x_{1}\right), d\left(x_{0}, x_{2}\right), 0\right) \\
& \leqslant g\left(D_{1}\left(T x_{0}, T x_{1}\right), d\left(x_{0}, x_{1}\right), p\left(x_{1}, T x_{1}\right), p\left(x_{0}, T x_{0}\right), p\left(x_{0}, T x_{1}\right), p\left(T x_{0}, x_{1}\right)\right) \\
& \leqslant g\left(D\left(T x_{0}, T x_{1}\right), d\left(x_{0}, x_{1}\right), p\left(x_{1}, T x_{1}\right), p\left(x_{0}, T x_{0}\right), p\left(x_{0}, T x_{1}\right), p\left(T x_{0}, x_{1}\right)\right) \leqslant 0
\end{aligned}
$$

From $\left(g_{2}\right)$, there exists $k \in(0,1)$ such that $d\left(x_{1}, x_{2}\right) \leqslant k d\left(x_{0}, x_{1}\right)$. Continuing in this way we produce a sequence $\left\{x_{n}\right\}$ in $X$ such that $x_{n+1} \subset T\left(x_{n}\right)$ and

$$
d\left(x_{n}, x_{n+1}\right) \leqslant k^{n} d\left(x_{0}, x_{1}\right) .
$$

It follows by induction that $d\left(x_{n}, x_{n+1}\right) \leqslant k^{n} d\left(x_{0}, x_{1}\right)$ for each $n \in \mathbb{N}$. Since

$$
\begin{aligned}
d\left(x_{n}, x_{m}\right) & \leqslant d\left(x_{n}, x_{n+1}\right)+d\left(x_{m}, x_{n+1}\right) \\
& \leqslant d\left(x_{n}, x_{n+1}\right)+d\left(x_{m}, x_{m}\right)+d\left(x_{n+1}, x_{m}\right) \\
& \leqslant d\left(x_{n}, x_{n+1}\right)+d\left(x_{n+1}, x_{n+2}\right)+d\left(x_{m}, x_{n+2}\right) \\
& \leqslant d\left(x_{n}, x_{n+1}\right)+d\left(x_{n+1}, x_{n+2}\right)+d\left(x_{m}, x_{m}\right)+d\left(x_{n+2}, x_{n+3}\right)+\cdots+d\left(x_{m-1}, x_{m}\right) .
\end{aligned}
$$

Then for $\mathrm{n}<\mathrm{m}$ we have

$$
d\left(x_{n}, x_{m}\right) \leqslant \sum_{i=0}^{m-n-1} d\left(x_{n+i}, x_{n+i+1}\right) \leqslant \sum_{i=n}^{m-1} k^{i} d\left(x_{0}, x_{1}\right) \leqslant \frac{k^{n}}{1-k} d\left(x_{0}, x_{1}\right) .
$$

Then the sequence $\left\{x_{n}\right\}$ is Cauchy. Since $(X, d)$ is complete, then there exists $x^{*} \in X$ such that $\lim _{n \rightarrow \infty} x_{n}=x^{*}$. By Lemma 3.9, we obtain the $\lim _{n \rightarrow \infty} x_{n+1}=x^{*}$. By Lemma 3.10 and Lemma 3.7, we get

$$
p_{\alpha}\left(T x^{*}, x^{*}\right) \leqslant p_{\alpha}\left(T x^{*}, x_{n+1}\right)+d\left(x^{*}, x_{n+1}\right) \leqslant D_{\alpha}\left(T x^{*}, T x_{n}\right)+d\left(x^{*}, x_{n+1}\right)=D_{\alpha}\left(T x^{*}, x_{n+1}\right)+d\left(x^{*}, x_{n+1}\right),
$$

for each $\alpha \in[0,1]$. Taking supremum on $\alpha$ in the last inequality, we obtain from the property $\left(g_{1}\right)$ of $G$ that

$$
g\left(p\left(T x^{*}, x_{n+1}\right), d\left(x^{*}, x_{n}\right), d\left(x_{n}, x_{n+1}\right), p\left(x^{*}, x^{*}\right)+d\left(T x^{*}, x^{*}\right), d\left(x^{*}, x_{n+1}\right), p\left(T x^{*}, x_{n}\right)\right)
$$




$$
\begin{aligned}
& \leqslant g\left(p\left(T x^{*}, x_{n+1}\right), d\left(x^{*}, x_{n}\right), d\left(x_{n}, x_{n+1}\right), p\left(x^{*}, T x^{*}\right), d\left(x^{*}, x_{n+1}\right), p\left(T x^{*}, x_{n}\right)\right) \\
& \leqslant g\left(D_{1}\left(T x^{*}, T x_{n}\right), d\left(x^{*}, x_{n}\right), p\left(x_{n}, T x_{n}\right), p\left(x^{*}, T x^{*}\right), p\left(x^{*}, T x_{n}\right), p\left(T x^{*}, x_{n}\right)\right) \\
& \leqslant g\left(D\left(T x^{*}, T x_{n}\right), d\left(x^{*}, x_{n}\right), p\left(x_{n}, T x_{n}\right), p\left(x^{*}, T x^{*}\right), p\left(x^{*}, T x_{n}\right), p\left(T x^{*}, x_{n}\right)\right) \leqslant 0 .
\end{aligned}
$$

As $n \rightarrow \infty$, we have that

$$
g\left(d\left(T x^{*}, x^{*}\right), 0,0, d\left(T x^{*}, x^{*}\right), 0, d\left(T x^{*}, x^{*}\right)\right) \leqslant 0 .
$$

By the condition $\left(g_{3}\right)$ of $G$, then $d\left(T x^{*}, x^{*}\right)=0$. So by Lemma 3.6 we conclude that $T$ has a fixed point.

Remark 3.12. Theorem 3.11 generalizes and improves Theorem 3.1 in [8] where $X$ is complete rq-metric space instead of $X$ being complete metric linear space.

Corollary 3.13. Let $(X, d)$ be complete rq-metric space, $\mathrm{x}_{0} \in \mathrm{X}$, and $\mathrm{T}: \mathrm{X} \longrightarrow \mathrm{W}^{*}(\mathrm{X})$ be a fuzzy mapping. If there exists $\mathrm{k} \in(0,1)$ such that

$$
\mathrm{D}(\mathrm{T} x, \mathrm{Ty}) \leqslant \mathrm{kd}(\mathrm{x}, \mathrm{y}) \text { for each } x, y \in X,
$$

then $\mathrm{T}$ has a fixed point.

\section{Acknowledgment}

The authors are grateful to the editor and reviewers for useful suggestions which improved the contents of this paper.

\section{References}

[1] M. Abbas, B. Damjanović, R. Lazović, Fuzzy common fixed point theorems for generalized contractive mappings, Appl. Math. Lett., 23 (2010), 1326-1330.

[2] H. M. Abu-Donia, Common fixed points theorems for fuzzy mappings in metric spaces under $\varphi$-contraction condition, Chaos Solitons Fractals, 34 (2007), 538-543.

[3] A. Azam, M. Arshad, I. Beg, Fixed points of fuzzy contractive and fuzzy locally contractive maps, Chaos Solitons Fractals, 42 (2009), 2836-2841.

[4] A. Azam, I. Beg, Common fixed points of fuzzy maps, Math. Comput. Model., 49 (2009), 1331-1336.

[5] I. Beg, M. A. Ahmed, Fixed point for fuzzy contraction mappings satisfying an implicit relation, Mat. Vesnik, 66 (2014), 351-356. 1.1, 1.2, 1.3, 1.5, 1.6, 1.7, 1.8

[6] R. K. Bose, D. Sahani, Fuzzy mappings and fixed point theorems, Fuzzy Sets and Systems, 21 (1987), 53-58.

[7] A. P. Farajzadeh, A. Kaewcharoen, S. Plubtieng, An Application of Fixed Point Theory to a Nonlinear Differential Equation, Abstr. Appl. Anal., 2014 (2014), 7 pages.

[8] S. Heilpern, Fuzzy mappings and fixed point theorem, J. Math. Anal. Appl., 83 (1981), 566-569. 1, 2.12, 3.12

[9] M. Imdad, J. Ali, A general fixed point theorem in fuzzy metric spaces via an implicit function, J. Appl. Math. Inform., 26 (2008), 591-603.

[10] E. Karapinar, B. Samet, Generalized $\alpha-\psi$-contractive type mappings and related fixed point theorems with applications, Abstr. Appl. Anal., 2012 (2012), 793-486.

[11] B. S. Lee, S. J. Cho, A fixed point theorem for contractive type fuzzy mappings, Fuzzy Sets and Systems, 61 (1994), 309-312.

[12] S. B. Nadler, Multivalued contraction mappings, Pacific J. Math., 30 (1969), 475-488. 1.4

[13] V. Popa, Fixed point theorems for implicit contractive mappings, Stud. Cercet. Ştiinţ. Ser. Mat. Univ. Bacău, 7 (1997), 127-133. 1

[14] R. A. Rashwan, M. A. Ahmed, Common fixed point theorems for fuzzy mappings, Arch. Math. (Brno), 38 (2002), 219-226.

[15] B. E. Rhoades, A common fixed point theorem for sequence of fuzzy mappings, Int. J. Math. Math. Sci., 8 (1995), $447-450$.

[16] L. A. Zadeh, Fuzzy sets, Inform. Control, 8 (1965), 338-353. 